This is the final peer-reviewed accepted manuscript of:

F. Cova et al., 'De Pulchritudine non est Disputandum? A cross-cultural investigation of the alleged intersubjective validity of aesthetic judgment', Mind \& Language 34, 2019, pp. 317-338.

The final published version is available online at:

https://onlinelibrary.wiley.com/doi/abs/10.1111/mila.12210

Rights / License:

The terms and conditions for the reuse of this version of the manuscript are specified in the publishing policy. For all terms of use and more information see the publisher's website.

This item was downloaded from IRIS Università di Bologna (https://cris.unibo.it/)

When citing, please refer to the published version. 


\title{
De Pulchritudine non est Disputandum? A cross-cultural investigation of the alleged intersubjective validity of aesthetic judgment
}

\author{
Florian Cova | Christopher Y. Olivola | Edouard Machery | Stephen Stich | David Rose | \\ Mario Alai | Adriano Angelucci | Renatas Berniūnas |Emma E. Buchtel | Amita Chatterjee | \\ Hyundeuk Cheon | In-Rae Cho | DanielCohnitz | Vilius Dranseika | Ángeles E. Lagos | Laleh \\ Ghadakpour | Maurice Grinberg | Ivar Hannikainen | Takaaki Hashimoto | Amir Horowitz | \\ Evgeniya Hristova | Yasmina Jraissati | Veselina Kadreva | Kaori Karasawa | Hackjin Kim | \\ Yeonjeong Kim | Minwoo Lee | Carlos Mauro | Masaharu Mizumoto | Sebastiano Moruzzi | \\ Jorge Ornelas | Barbara Osimani | Carlos Romer | Alejandro Rosas | Massimo Sangoi | \\ Andrea Sereni | Sarah Songhorian | Paulo Sousa | Noel Struchiner | Vera Tripodi | Naoki \\ Usui | Alejandro V. del Mercado | Giorgio Volpe | Hrag A. Vosgerichian | Xueyi Zhang | \\ Jing Zhu
}

\begin{abstract}
Since at least Hume and Kant, philosophers working on the nature of aesthetic judgment have generally agreed that common sense does not treat aesthetic judgments in the same way as typical expressions of subjective preferences-rather, it endows them with intersubjective validity, the property of being right or wrong regardless of disagreement. Moreover, this apparent intersubjective validity has been taken to constitute one of the main explananda for philosophical accounts of aesthetic judgment. But is it really the case that most people spontaneously treat aesthetic judgments as having intersubjective validity? In this paper, we report the results of a cross-cultural study with over 2,000 respondents spanning 19 countries. Despite significant geographical variations, these results suggest that most people do not treat their own aesthetic judgments as having intersubjective validity. We conclude by discussing the implications of our findings for theories of aesthetic judgment and the purpose of aesthetics in general.
\end{abstract}

\section{1 | INTRODUCTION}

One traditional aim of philosophical aesthetics is to explain the nature of aesthetic judgments (that is: judgments that attribute to their object aesthetic properties such as "beautiful," "ugly," "elegant," etc.). Indeed, it is traditionally thought that the existence of aesthetic judgments calls for a philosophical explanation because such judgments seem to present a unique combination of features: They are often considered subjective (i.e., they stem from personal experiences, and as such, only describe or express individual and arbitrary preferences) and they also appear to possess intersubjective validity (i.e., they are considered to be right or wrong, correct or incorrect for people in general, regardless of disagreement, thereby opening the possibility that some people might be wrong). That we naturally and spontaneously consider that everyday aesthetic judgments combine these two properties is genera ally deemed one of the main explananda for a proper and satisfying account of aesthetic judgment.

\section{1 | The "big question in aesthetics": Intersubjective validity}

That aesthetic judgments are both subjective and intersubjectively valid is often taken as a starting point by philosophical accounts of aesthetic judgment. But why assume in the first place that aesthetic judgments have such properties? According to some philosophers: because this is supposed to be common sense, and to be reflected in our everyday practices involving aesthetic judgment.

This, at least, is the reason proposed in the two historical references that guide the philosophical debate on the nature of aesthetic judgment. The first is Hume's essay "On the Standard of Taste," which famously 
described common sense as torn between conflicting considerations when it comes to ranking and comparing aesthetic judgments:

To seek the real beauty, or real deformity, is as fruitless an enquiry, as to pretend to ascertain the real sweet or real bitter. According to the disposition of the organs, the same object may be both sweet and bitter; and the proverb has justly determined it to be fruitless to dispute concerning tastes. It is very natural, and even quite necessary, to extend this axiom to mental, as well as bodily taste; and thus common sense, which is so often at variance with philosophy, especially with the sceptical kind, is found, in one instance at least, to agree in pronouncing the same decision.

But though this axiom, by passing into a proverb, seems to have attained the sanction of common sense; there is certainly a species of common sense which opposes it, at least serves to modify and restrain it. Whoever would assert an equality of genius and elegance between OGILBY and MILTON, or BUNYAN and ADDISON, would be thought to defend no less an extravagance, than if he had maintained a mole-hill to be as high as TENERIFFE or a pond as extensive as the ocean. Though there may be found persons, who give the preference to the former authors; no one pays attention to such a taste; and we pronounce without scruple the sentiment of these pretended critics to be absurd and ridiculous. The principle of the natural equality of tastes is then totally forgot, and while we admit it on some occasions, where the objects seem near an equality, it appears an extravagant paradox, or rather a palpable absurdity, where objects so disproportioned are compared together. (Hume, 1762, pp. 209-210)

Thus, although common sense sometimes treats aesthetic judgments as mere expressions of subjective preferences, it also acknowledges that they possess one property that distinguishes them from expressions of subjective preferences: intersubjective validity. In other words, aesthetic judgment are supposed to differ from expressions of subjective preferences to the extent that (a) they can be said to be correct or incorrect and (b) their correctness does not depend on who utters them. The same idea is famously defended by Kant (1790/1928), who makes it one of the main themes of the first part of his Critique of Judgment:

... when [a man] puts a thing on a pedestal and calls it beautiful, he demands the same delight from others. He judges not merely for himself, but for all men, and then speaks of beauty as if it were a property of things. Thus he says that the thing is beautiful; and it is not as if he counts on others agreeing with him in his judgment of liking owing to his having found them in such agreement on a number of occasions, but he demands this agreement of them. He blames them if they judge differently, and denies them taste, which he still requires of them as something they ought to have; and to this extent it is not open to men to say: Every one has his own taste. (Kant, 1790/1928, p.52)

So, the idea is that common sense seems to be bouncing between two opposing commitments. On the one hand, we seem to consider that aesthetic judgments are the mere results and expressions of personal and individual experiences. This is what underlies everyday sayings such as "to each his/her taste" and "it's only a matter of taste." This is also what is revealed, according to certain philosophers, by the fact that we do not value aesthetic testimony and have the intuition that one cannot know whether a certain object or person is beautiful if one has not personally experienced it (see Robson, 2012, for a review). On the other hand, we seem to think that certain aesthetic judgments are better than others, as shown by our willingness to distinguish between "good taste" and "bad taste." This is also supposed to be the presupposition that makes certain practices intelligible, such as the fact that people discuss and argue about the aesthetic qualities of objects (Kivy, 2015).

How aesthetic judgments (or indeed any judgment) could in fact combine these two properties is, at first sight at least, a puzzle. Still, most philosophers working in aesthetics seem to accept this fact as a basic one, as can be seen in recent papers in the area:

All aesthetic judgements, whether descriptive, evaluative or some combination of the two, and whatever they might be about, whether works of art, artefacts of other kinds, or natural things, declare themselves to be, not mere announcements or expressions of personal responses to the objects of judgement, but claims meriting the agreement of others. Despite the frequent appeal in 
everyday life to the nihilistic interpretation of the saying 'It's all a matter of taste', the doctrine of aesthetic nihilism - the view that such claims are never warranted - does not merit serious attention. (Budd, 2007, p. 333)

"There is no accounting for taste" is a well-known proverb by which the lack of unanimity in matters of taste and the impossibility of disputing them is aptly expressed. At the same time, however, when one is touched by the beauty of a sunset, a Beethoven string quartet, a novel by James Joyce, or a painting by Giorgio Morandi, one cannot help thinking that the experienced feeling of pleasure ought to be shared by others. Notwithstanding its logical singularity, the pure judgement of taste - i.e. the judgement of beauty - requires or "demands" everyone else's agreement. Yet the demand for universal agreement is very peculiar, since it cannot be based on conceptual arguments or proofs and is only determined by one's own feeling of pleasure or displeasure. (Vandenabeele, 2008, p. 410)

What comes to be known as the "paradox of taste" thus centres around the following problem: how are we to reconcile the subjective pleasure that is undeniably part of aesthetic experience with the objective aspirations of the very judgements resulting from that pleasure? How are we to account for, let alone overcome, this seemingly irreconcilable duality between the coincident subjectivity and objectivity of taste? The question arises as judgements of aesthetic taste do not seem to be like most judgements of taste in that they seem to amount to more than mere reports of subjective mental states. Yet at the same time, they cannot be said to pick out an objective property, at least as such things are conceived traditionally. (Schellekens, 2009, p. 738)

Of course, some philosophers working in aesthetics argue that it is wrong to attribute intersubjective validity to aesthetic judgments, but even they tend to share the idea that common sense does attribute such validity to aesthetic judgments. Thus, the notion that aesthetic judgments spontaneously appear to possess intersubjective validity is generally accepted as the default point, in virtue of being part of our everyday understanding of these judgments.

\section{2 | Explaining intersubjective validity}

It is puzzling how a judgment could both be subjective and have intersubjective validity. Solving this puzzle has generally been seen as one of the main questions that a proper account of aesthetic judgment must address. As a recent encyclopedia entry on aesthetic judgment puts it:

in respect of normativity, judgments of taste are like empirical judgments and unlike judgments of niceness or nastiness, but in respect of subjectivity, judgments of taste are unlike empirical judgments and like judgments of niceness or nastiness. So we have a three-fold division: empirical judgments, judgments of taste, and judgments of niceness or nastiness. And judgments of taste have the two points of similarity and dissimilarity on each side just noted.

As Kant recognized (more or less following Hume), all this is a point from which to theorize. The hard question is whether, and if so how, such a subjectively universal judgment is possible. On the face of it, the two characteristics are in tension with each other. Our puzzle is this: what must be the nature of pleasure in beauty if the judgments we base on it can make claim to correctness? This is the Big Question in aesthetics. Kant set the right agenda for aesthetics. (Zangwill, 2010)

Both realism and non-realism are on a par as far as the experiential aspect of aesthetics is concerned. But when it comes to explaining the normativity of aesthetic judgements, the realist is ahead [...] I conclude that folk aesthetics is thus realist. Whether or not the tacit folk metaphysical commitment to aesthetic facts or states of affair is justified is another matter, but our aesthetic judgments presuppose that metaphysics. What is not an option is holding some non-realist view, be it Humean, Kantian or dispositional, while we can unproblematically retain our ordinary practice of making aesthetic judgments. (Zangwill, 2001) 
The supposition that aesthetic properties are objective also explains better how we talk about them than does the projection theory. For example, people involved in disputes about aesthetic properties act as though they think that they are disagreeing about the real properties of objects. They behave as though they think that there is a fact of the matter to be determined. They speak as if one side of the disagreement is right and the other wrong. So, they, at least, must believe that aesthetic properties are objective. That is the way of understanding their behaviour that renders it most intelligible. On the other hand, if disputants are simply trading projections, we would have to say that their behaviour is ultimately irrational. And it is far from clear that the sceptics' arguments are compelling enough to warrant such wholesale suspicion of irrationality. (Caroll, 1999, p. 117)

However, endorsing aesthetic realism is not the only way to take seriously the apparent intersubjective validity of aesthetic judgments. Kant himself, while endorsing intersubjective validity, rejected aesthetic realism (or any form of aesthetic objectivism) and instead tried to explain the intersubjective validity of aesthetic judgment by arguing that aesthetic judgments differ from other subjective judgments to the extent that they do not stem from personal drives and interests, but rather from the free play of universally shared faculties (Kant, 1790/1928, p. 52). Similarly, Goldman advances a form of aesthetic antirealism, according to which aesthetic properties are mind-dependent, while trying to retain the idea that these judgments have intersubjective validity by making their correctness depend on the reactions of ideal critics (Goldman, 1995), while Todd defends a quasi-realist view of aesthetic properties, but still tries to do justice to the normative claims of aesthetic judgment (Todd, 2004; see also Hopkins, 2001).

The alternative position is of course to turn "sceptic" and claim that people are wrong when they attribute intersubjective validity to aesthetic judgment. This usually involves advancing an error theory that explains away the apparent intersubjective validity of aesthetic judgment. For example, Mackie is well known for his moral error theory, according to which we project moral values onto the world, rather than discover them. It turns out that he also thinks the same kind of account can be applied to aesthetic properties (Mackie, 1990, p. 15). Such an account would both deny that aesthetic judgments have intersubjective validity and explain why people think that intersubjective validity is a property of aesthetic judgments: It is because they (wrongly) take aesthetic properties to be part of the fabric of the world. A similar account is proposed by Genette, who denies the intersubjective validity of aesthetic judgment, but explains its perceived normativity by a process of "objectivation," whereby we are led to attribute our enjoyment to aesthetic things themselves, which is ultimately a cognitive illusion (Genette, 1997).

The important point, however, is that all sides of the dispute seem to accept that aesthetic judgments naturally appear to have intersubjective validity, and that this needs to be explained, thus putting pressure on philosophical accounts of aesthetic judgment.

\subsection{Questioning the intersubjective validity of aesthetic judgments}

However, is it true that we ordinarily attribute intersubjective validity to aesthetic judgments? Is it true that common sense endorses the idea that aesthetic judgments can be right or wrong in general, and not only for the person who forms them? Is the "Big Question of aesthetics" the right one? Despite all the support it has received from philosophers, this basic premise has only recently been put into question and empirically investigated, following the methods of what is now called "experimental philosophy of aesthetics" (Cova, Garcia \& Liao, 2015).

Across three studies, Cova and Pain (2012) probed people's beliefs about the intersubjective validity of aesthetic judgments. In their first two studies, they gave 60 French undergraduates 15 vignettes describing several kinds of disagreements between two interlocutors coming from different cultures: typical subjective disagreement (e.g., disagreement about whether some food tastes good or bad), typical factual disagreement (e.g., disagreement about whether Proust is the author of In Search of Lost Time), and aesthetic disagreement (e.g., whether a given painting, song, or landscape is beautiful or ugly - this included famous works of arts such as Da Vinci's Mona Lisa, or Beethoven's For Elise). For each kind of disagreement, respondents were asked to indicate which of the four following possibilities best described the situation:

a. One of the interlocutors is right while the other is wrong.

b. Both are right. 
c. Both are wrong.

d. Neither is right or wrong. It makes no sense to speak in terms of correctness in this situation. Everyone is entitled to his/her own opinion.

As expected, most respondents chose (a) for factual disagreements (showing that they did not inte pret the question as merely asking them about the characters' personal preferences), and (d) for subjective disagreements (showing that the measure was sensitive enough to capture the perceived subjectivity of judgments typically considered as such by philosophers). However, it also turned out that most respondents chose (d) for aesthetic disagreements; in fact, the likelihood of choosing (d) did not significantly differ between subjective and aesthetic disagreements. This suggests that, contrary to accepted philosophical wisdom, laypeople do not view aesthetic judgments as possessing intersubjective validity.

However, there is an alternative explanation for these results: maybe the reason respondents did not choose answer (a) in these situations was that they were not personally involved, or were not familiar with the works of art discussed in these vignettes. To control for this possibility, Cova and Pain (2012) designed a third study in which 20 French respondents were first instructed to describe an object they personally found very beautiful, then asked to imagine that someone was disagreeing with them by claiming that said object was not at all beautiful. Here again, respondents were asked to choose, among answers (a) to (d), the one they believed best described the situation. As with their first two studies, Cova and Pain found that very few respondents (10\%) chose answer (a), and that most of them instead chose answer (d).

Taken at face value, these results strongly suggest that, contrary to what is generally assumed by aestheticians, people do not attribute intersubjective validity to aesthetic judgments. However, these studies are limited by the fact that they relied on very small and geographically narrow samples: a grand total of 80 respondents, all of them students recruited in Paris' Quartier Latin. As critics have pointed out, it would be foolish to draw broad inferences about general attitudes from such a limited sample (Henrich, Heine \& Norenzayan, 2010; Réhault, 2013). One may also wonder whether these answers merely reflect some kind of superficial relativism common among Western students (Pouivet, 2006).

The aim of this paper is to investigate whether Cova and Pain's (2012) original findings generalize to a much larger and much more diverse sample, as well as across geographic areas. In doing so, we provide a much stronger test of the hypothesis that common sense is committed to the intersubjective validity of aesthetic judgments.

\section{2 | EMPIRICALLY INVESTIGATING FOLK AESTHETICS ON A CROSS-CULTURAL SCALE}

\section{$2.1 \mid$ Method}

As part of an international collaboration, 2,392 respondents $\left(\mathrm{M}_{\mathrm{age}}=31.28, \mathrm{SD}_{\text {age }}=14.64 ; 53.2 \%\right.$ female, $46.0 \%$ male, $0.8 \%$ not indicating gender) drawn from 25 populations in 19 countries distribf uted across four continents (the Americas, Europe, and Asia) took part in this study (see Table 1). Respondents were presented with a battery of questions, including the ones of interest (described below), either in a paperpencil or web-based format.

The questions of interest were the following (and presented in the order shown):

Question 1. Describe something (e.g., a natural object, or some work of art) that you find very beautiful.

Question 2. Now, imagine that you meet someone and that this person says to you that he does not find this thing beautiful at all. In your personal opinion, which of the following best describes this situation:

1. One of you is correct while the other is not.

2. Both of you are correct.

3. Neither is correct. It makes no sense to talk about correctness in this situation.

Question 3. How certain are you of your response to Question 2 on a $(0-100) \%$ scale, with low 
numbers indicating that you are not sure and high numbers indicating that you are sure?

I am $\%$ certain of my response.

Questions were translated into the respondents' primary language, as a function of where data were collected (see Table 1).

TARLE 1 Demographic infoemation about the study's respondents (after exclusion), including countries in which data were collected, nature of the sample (sbodents vx. noe-stidents), mode of survey administrations (paper-peacil vx. web-based; volunieers vx. paid participants; survey language)

\begin{tabular}{|c|c|c|c|c|c|c|}
\hline Covantry & Sample & Stadents? & Method & Pagment & Lanquage & $\boldsymbol{N}$ \\
\hline \multicolumn{7}{|l|}{ Europe } \\
\hline Bulgaria & Non-students & $\mathbf{N}$ & Web-based & Volumeers & Bulgarian & 123 \\
\hline France & NA & $\mathrm{N}$ & Web-based & $\begin{array}{l}\text { Compensutice } \\
\text { and volunteers }\end{array}$ & Fiench & 207 \\
\hline Germany & NA & $\mathbf{N}$ & Web-based & Compersution & Germea & 111 \\
\hline Inaly & NA & $\mathbf{Y}$ & Paper-pencil & Volumeers & Inalian & 101 \\
\hline Lithuaaia & Non-students & $\mathrm{N}$ & Paper-pencil & Volumeers & Lithuantan & 80 \\
\hline Lithuaaia & Studenss & $\mathbf{Y}$ & Paper-pencil & Volumeers & Lithuantan & 80 \\
\hline Portugal & NA & $\mathbf{Y}$ & Paper-pencil & Volumeers & Pertuguese & 60 \\
\hline Spain & NA & $\mathbf{N}$ & Web-based & Compersutice & Spanish & 146 \\
\hline Swirnerlund & Non-students & $\mathrm{N}$ & $\begin{array}{l}\text { Paper-pencil and } \\
\text { web-bused }\end{array}$ & Volumeers & Fiench & 37 \\
\hline Swicrerland & Studenss & $\mathbf{Y}$ & $\begin{array}{l}\text { Paper-pencil and } \\
\text { web-bused }\end{array}$ & $\begin{array}{l}\text { Compensutice } \\
\text { and volunteers }\end{array}$ & Fiench & 10 \\
\hline UK & NA & $\mathbf{N}$ & Web-based & Compersutice & Engliah & 142 \\
\hline \multicolumn{7}{|l|}{ Middle East } \\
\hline Iran & NA & $\mathrm{N}$ & Paper-pencil & Volumeers & Persiaa & 50 \\
\hline Istael & & $\mathbf{Y}$ & Web-based & Volumeers & Hebuew & 82 \\
\hline \multicolumn{7}{|c|}{ Central and North America } \\
\hline Mesico & NA & $\mathrm{N}$ & Paper-pencil & Volumeers & Spanish & 91 \\
\hline USA & NA & $\mathbf{N}$ & Web-based & Compersution & English & 125 \\
\hline \multicolumn{7}{|l|}{ Seuth America } \\
\hline Bracil & NA & $\mathbf{Y}$ & Paper-pencil & Volumeers & Pertuguese & 80 \\
\hline \multicolumn{7}{|l|}{ East Asü } \\
\hline Chin & Sample 1 & $\mathbf{Y}$ & Paper-pencil & NA & $\mathrm{NA}$ & 90 \\
\hline Chisu & Guangzhos & $\mathbf{Y}$ & Paper-pencil & Volumeers & Chinese, simplified & 95 \\
\hline Chisu & Mainland & $\mathrm{N}$ & Web-based & Compersutice & Chinese, simplified & 101 \\
\hline Heng Kong & NA & $\mathbf{Y}$ & Web-based & Compensutioe & Chinese, traditicenal & 100 \\
\hline Japan & Non-students & $\mathrm{N}$ & Web-based & Compensutice & Japanese & 100 \\
\hline Japan & Studenss & $\mathbf{Y}$ & Paper-pencil & Volumeers & Japanese & 170 \\
\hline Sounh Koeta & NA & $\mathrm{N}$ & Web-based & Compersution & Koecan & 91 \\
\hline \multicolumn{7}{|c|}{ South and Southeas Asia } \\
\hline Indcenesia & NA & $\mathbf{Y}$ & Paper-pencil & Compersutice & Indonesian & 100 \\
\hline India & NA & $\mathbf{Y}$ & Paper-pencil & Volumeers & Beagali & 100 \\
\hline
\end{tabular}

Question 2 is supposed to probe whether respondents attribute intersubjective validity to their own aesthetic judgments. Answer 1 expresses the belief that aesthetic judgments indeed have intersubjective validity, to the extent that they can be correct or incorrect, and that this correctness does not depend on who formulates those judgments. Answer 2 is supposed to reflect subjectivist commitments, by expressing the belief that aesthetic judgments can be considered correct or incorrect, but that two apparently contradictory judgments 
can both be correct as long as they are not formed by the same person. Finally, Answer 3 reflects the nihilist approach, according to which aesthetic judga ments cannot be ascribed correctness or incorrectness. If the philosophical consensus that common sense embraces intersubjective validity is right, we should expect most respondents to choose Answer 1.

\section{$2.2 \mid$ Results}

\subsubsection{Intersubjective validity}

Overall, only 7\% of our respondents chose Answer 1, 41\% chose Answer 2, and 52\% chose Answer 3. Moreover, ratings of confidence were significantly lower when respondents chose Answer $1(\mathrm{M}=78.9$, SD $=24.0)$ than when they chose Answer $2(\mathrm{M}=86.9, \mathrm{SD}=20.5)(\mathrm{t}[1140]=4.54, \mathrm{p}<.001, \mathrm{~d}=.38)$, or Answer $3(\mathrm{M}=91.1, \mathrm{SD}=16.0)(\mathrm{t}[1406]=8.69, \mathrm{p}<.001, \mathrm{~d}=.72)$. Confidence ratings were also higher for Answer 3 than for Answer $2(\mathrm{t}[2214]=5.49, \mathrm{p}<.001, \mathrm{~d}=.24)$. This suggests that, contrary to the philosophical consensus, most people do not endorse the idea that aesthetic judgments (or, at least, judgments of beauty, which constitute a paradigmatic case of aesthetic judgment) have intersubjective validity.

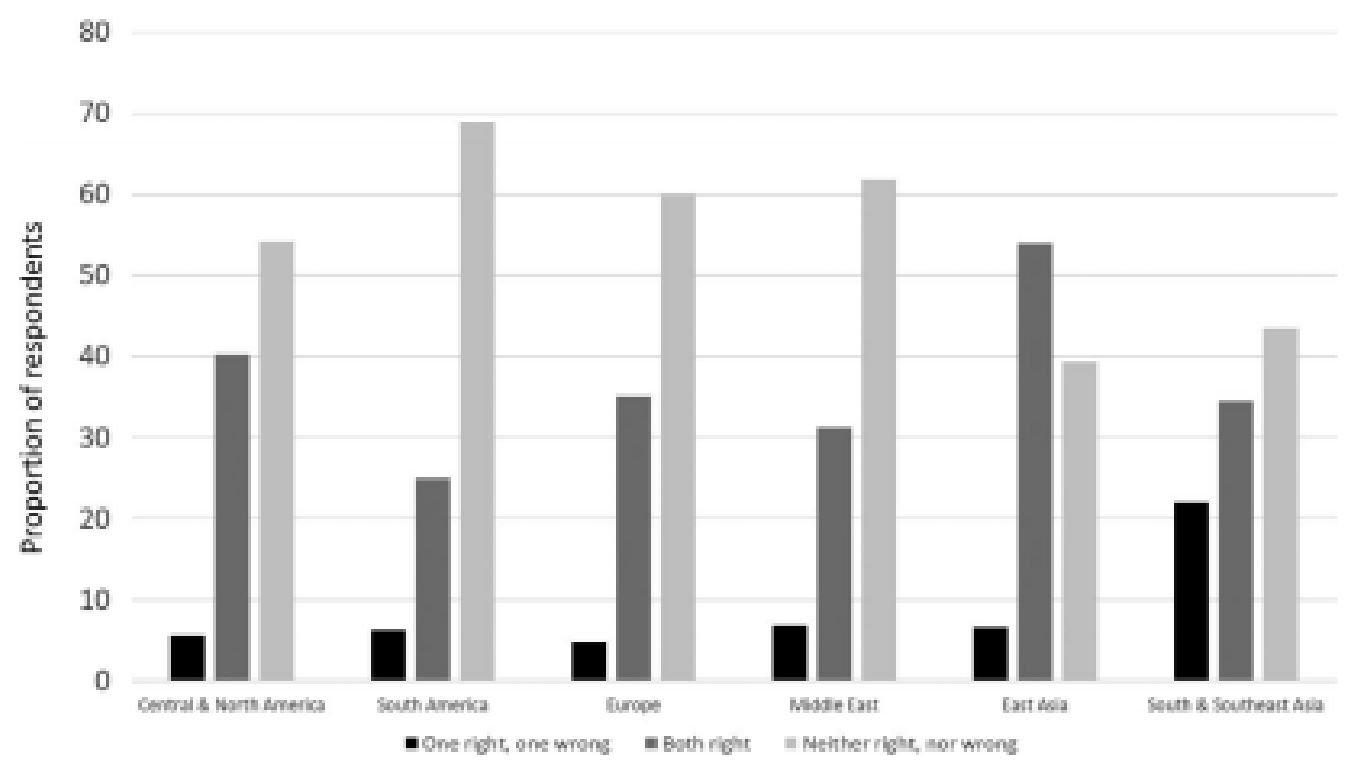

FIGURE 1 Distribution of respondents' answers across geographic areas

\subsection{2 | Demographic variations}

Do these results hold for all populations? We grouped respondents into six geographic areas, depending on the country they were tested in: Europe (Bulgaria, France, Germany, Italy, Lithuania, Portugal, Spain, Switzerland, UK), Middle East (Iran, Israel), Central and North America (Mexico, USA), South America (Columbia, Brazil), East Asia (China, Hong Kong, Japan, South Korea), and finally South and Southeast Asia (India, Indonesia). We then compared the distributions of respondents' answers across these geographic areas (see Figure 1).

A chi-square test revealed significant differences in the distributions of answers across geographic areas; $\chi^{2}(10, \mathrm{~N}=2,392)=166.64, \mathrm{p}<.001, \mathrm{VCramer}=.19$. A second chi-square test, collapsing Answers 2 and 3 into a single category, revealed that the proportion choosing Answer 1 also varied across geographic areas; $\chi^{2}(5, \mathrm{~N}=2,392)=77.44, \mathrm{p}<.001, \mathrm{VCramer}=.18$. The greatest difference in percentages of respondents choosing Answer 1 is between Europe (4.8\%) and South and Southeast Asia (22.0\%) - a difference of $17.2 \% ; \chi^{2}(1, \mathrm{~N}=1,221)=67.9, \mathrm{p}<.001, \mathrm{VCramer}=.24$.

However, despite these differences, there is a consistent pattern: Answer 1 is the least chosen option in all geographic areas. Even in the South and Southeast Asia sample, the proportion choosing Answer 1 was significantly below chance (if we assume chance $=33 \%$ ), according to a chi-square test; $\chi^{2}(1, \mathrm{~N}=200)=$ $10.9, \mathrm{p}<.001, \mathrm{VCramer}=.16$. So, although there is important variation across geographic areas in the percentage of people choosing Answer 1, it nonetheless remains the least chog sen answer. This puts 
considerable pressure on the philosophical consensus, according to which most people naturally tend to attribute intersubjective validity to aesthetic judgments.

This is not to say that all geographic areas think the same way about aesthetic judgment. Indeed, though all geographic areas seem to agree in (mostly) rejecting the intersubjective validity of aesthetic judgments, there are considerable differences in which answer ( 2 or 3$)$ they do tend to prefer. While some geographic areas seem to mostly favour Answer 2 (e.g., East Asia, 54.0\%), others seem to favour Answer 3 (e.g., South America, $68.8 \%$ ). The difference between geographic areas in the proportions selecting a particular answer reached 29.0\% for Answer 2 (South America vs. East Asia) and 29.4\% for Answer 3 (South America vs. East Asia). These differences are greater than the differences in percentages of respondents endorsing Answer 1, showing that there is no cross-cultural consensus on whether aesthetic judgments should be considered as having correctness conditions. Why some geographic areas favour subjectivism (Answer 2) over nihilism (Answer 3), or nihilism over subjectivism should be the focus of future research.

Variations across countries, rather than broad geographic areas, are displayed in Figure 2.

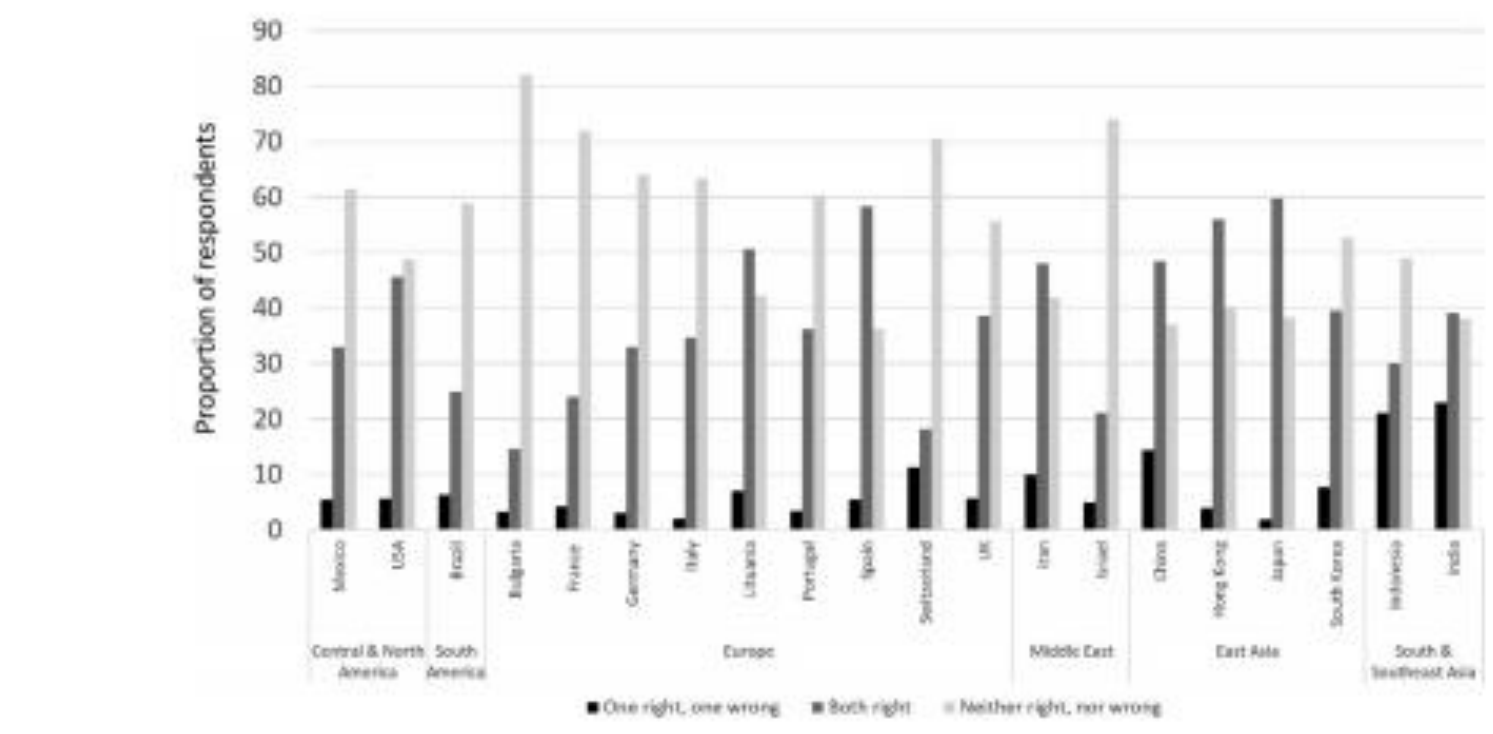

FIGURE 2 Distribution of answers across countries

\subsubsection{Individual determinants of meta-aesthetics commitments: Three hypotheses}

Our results show that, contrary to the claim of most philosophers, most people do not perceive aesthetic judgments as having intersubjective validity; rather, they ascribe to them only subjective validity, or no validity at all. In this way, our respondents seem to differ from professional philosophers. Indeed, in the PhilPapers Survey, a questionnaire completed by more than 3,000 philosophers (Bourget \& Chalmers, 2014), one question bore on the objectivity of aesthetic value:

Aesthetic value: objective or subjective?

- Objective

- Subjective

- Other

Bourget and Chalmers' results indicate that $41.0 \%$ of respondents chose the "objective" answer, $34.5 \%$ chose the "subjective" answer, and the remaining $24.5 \%$ chose the "other" answer. Though committing oneself to the objectivity of aesthetic values is not the same as accepting the intersubjective validity of aesthetic judgment, there is a close connection between both claims. As such, Bourget and Chalmers' results seem to indicate that philosophers are more likely to endorse the intersubjective validity of aesthetic judgment than the general population. The question is: why?

In what follows, we test three different possible answers to this question. The first possible answer we test is that professional philosophers are more likely than the general population to have the skills required for a full appreciation of works of art, and other objects of aesthetic appreciation. The second one is that 
professional philosophers are more likely than the general population to be cognitively reflective, and thus more likely to reject ideas that seem intuitively obvious but are ultimately misleading. The third one is that exposure to philosophy itself is what explains the difference between professional philosophers and the general population. We use the term "exposure" to mean both the potential effect of greater experience (e.g., more coursework) in philosophy and the potential effect of selecting into philosophy as a field of study (i.e., the unobserved characteristics of individuals who deliberately expose themselves to the questions and methods in philosophy).

To test all three hypotheses, we conducted a series of logistic regressions, in which we regressed the likelihood of providing Answer 1 on one of the variables of interest (education, cognitive reflectivity, or exposure to philosophy), while simultaneously controlling for a number of other factors: gender (with female as the reference category), age, country (with the USA as the reference category), whether the survey was web-based (as opposed to paper-pencil), and whether the sample came from a student population (as opposed to the general population).

\subsection{4 | First hypothesis: Education}

A first explanation for the difference between philosophers and the general population might be that only those with enough aesthetic training are able to perceive the intersubjective validity of aesthetic judgments, and that it is their judgments we should take into account. So, does greater exposure to art (for example) and higher aesthetic sensitivity increase belief in the intersubjective validity of aesthetic judgment?

Unfortunately, we cannot directly answer this question here, as we had no measure of aesthetic training or exposure, and there is no international measure of "aesthetic literacy" available. A good proxy, however, could be one's education level. It seems reasonable to expect people with higher education levels to also have higher aesthetic knowledge, particularly in the domain of art. In our sure vey, we asked respondents to report their education level:

What is your education level?

1. Grade/elementary school

2. High school

3. Some college or university

4. College or university degree

5. Graduate degree, Master's

6. $\mathrm{PhD}$

Table 2 presents the distribution of respondents' responses as a function of education level, and suggests that people with higher education levels are not more likely to select Answer 1. To more rigorously examine the relationship between education level and the likelihood of selecting Answer 1, we regressed the latter on the former, while simultaneously controlling for a host of other factors (as explained above). Entering education level as a continuous variable (i.e., a 1-6 scale, corresponding to the six categories in our education question) revealed that having more education predicted a significant decrease in the likelihood of selecting Answer 1 $\left(\right.$ beta $\left.=-24.6 \%,{ }^{1} \mathrm{p}<.01\right)$.

\footnotetext{
${ }^{1}$ We present the coefficient values of our logistic regressions as changes in the odds of selecting Answer 1. For continuous predictors, these numbers represent the change in odds of selecting Answer 1 associated with a 1-point increase in the predictor. For dummy-coded (i.e., categorical) predictors, these numbers represent the change in odds of selecting Answer 1 associated with a shift from the reference category to the target category.
} 
TABLE 2 Distribution of answers as a function of education level

\begin{tabular}{|lccll|}
\hline Education level & N & Answer 1 (\%) & Answer 2 (\%) & Answer 3 (\%) \\
\hline Gradefelementary school & 62 & 6.5 & 38.7 & 54.8 \\
\hline High school & 454 & 10.1 & 36.6 & 53.3 \\
\hline Some college or university & 834 & 7.2 & 42.0 & 50.1 \\
\hline College or university degree & 695 & 6.2 & 43.9 & 49.9 \\
\hline Graduate degree, Master's & 250 & 3.6 & 34.4 & 62.0 \\
\hline PhD & 58 & 5.2 & 46.6 & 48.3 \\
\hline
\end{tabular}

However, because it is not clear that education level, as we measured it, constituted a truly continuous variable, we ran a second logistic regression, treating education level as a categorical variable. Specifically, we replaced the continuous measure of education with four dummy variables, corresponding to (a) having completed some college or university coursework (but no degree), (b) having a college or university degree, (c) having a graduate degree or master's degree (but not a $\mathrm{PhD}$ ), and (d) having a $\mathrm{PhD}$. The reference (or baseline) group was thus individuals who had never gone to college or university. Results of this second regression revealed that all four higher education categories were directionally negative predictors of selecting Answer 1. Specifically, having a graduate degree or master's degree was a significant negative predictor $(-71.2 \%, \mathrm{p}<.01)$, while having a college or university degree was a marginally significant negative predictor $(-44.9 \%, \mathrm{p}=.05)$. Although the coefficients associated with having some college or university education $(-38.6 \%, \mathrm{p}=.13)$ or a $\mathrm{PhD}(-34.4 \%, \mathrm{p}=.51)$ were not significant, they were clearly not positive. Overall, compared to individuals who received no college education, those who attended college and those who also attended graduate school were less likely to select Answer 1.

Thus, if we consider that education level is a good proxy for exposure to art and aesthetic knowledge, it does not seem that the presence of such skills can explain why philosophers seem to be more likely to believe in the intersubjective validity of aesthetic judgment than non-philosophers.

\subsubsection{Second hypothesis: Cognitive reflectivity}

In a recent paper, Livengood, Sytsma, Feltz, Scheines and Machery (2010) found that philosophers tended in general to have higher scores on the cognitive reflection test (CRT; see Frederick, 2005). This test measures what Livengood et al. referred to as "cognitive reflectivity," which is a disposition to challenge one's own intuitions whenever presented with a novel problem, rather than simply relying on whatever first comes to mind. Two possible explanations for their results are that (a) training in philosophy increases one's cognitive reflectivity, or (b) that people with higher cognitive reflectivity might be more likely to engage in philosophy. Either way, the difference between philosophers and non-philosophers might be explained by (a) people with training in philosophy having higher levels of cognitive reflectivity and (b) people with higher cognitive reflectivity being more likely to reject the apparent subjectivity of aesthetic judgments and ascribe to them intersubjective validity.

In our survey, cognitive reflectivity was measured through the use of three math problems similar to the one below (see Frederick, 2005):

A bat and a ball cost $\$ 1.10$ in total. The bat costs $\$ 1.00$ more than the ball. How much does the ball cost? cents.

Here, the correct answer is $\$ 0.05$, but being able to find it requires inhibiting the intuitive (but incorrect) answer: $\$ 0.10$.

Respondents were attributed 1 point per correct answer, yielding a CRT score ranging from 0 to 3 . Respondents' CRT scores as a function of the answer they selected for the aesthetic question are presented in Table 3, and suggest that respondents with higher CRT scores were in fact less likely to select Answer 1. 
TABLE 3 Distribution of answers as a function of cognitive reflection test (CRT) score

\begin{tabular}{|c|c|c|c|c|}
\hline CRT score & $\boldsymbol{N}$ & Answer 1 (\%) & Answer $2(\%)$ & Answer 3 (\%) \\
\hline 0 & 771 & 10.9 & 39.0 & 50.1 \\
\hline 1 & 470 & 6.6 & 37.9 & 55.5 \\
\hline 2 & 463 & 3.5 & 43.6 & 52.9 \\
\hline 3 & 651 & 4.8 & 43.5 & 51. \\
\hline
\end{tabular}

Additionally, to ensure that respondents' performance on CRT was really due to their ability to inhibit intuitive answers, and not simply to their mathematical skills (or lack thereof), we measured their algebra skills by having them answer the following question: "If $3 x+2=17$, then what is $x$ equal to?"

To more rigorously examine the relationship between cognitive reflectivity and likelihood of selecting Answer 1, we regressed the latter variable on CRT score (a continuous variable) and whether the algebra question was correctly solved (a dummy variable), while simultaneously controlling for the other factors described above. This logistic regression revealed that scoring higher on the CRT was actually a significant negative predictor of selecting Answer $1(-22.6 \%, \mathrm{p}<.01)$. Moreover, correctly solving the algebra problem was also a (marginally significant) negative predictor of selecting Answer $1(-42.9 \%, \mathrm{p}=.06)$.

Thus, higher cognitive reflectivity does not predict higher endorsement of the intersubjective validity of aesthetic judgment. Quite the contrary, in fact.

\subsubsection{Third hypothesis: Exposure to philosophy}

If higher education levels and CRT scores actually predict a decrease in the likelihood of perceiving the intersubjective validity of aesthetic judgment, how are we to explain the difference between philosophers and non-philosophers? One possibility is that greater exposure to philosophy could be the distinguishing factor. This potential effect of exposure could come in two forms: (a) an exogenous exposure effect, whereby the practice of philosophy itself (e.g., more coursework) makes people more likely to perceive aesthetic judgments as having some sort of intersubjective validity, and (b) an endogenous exposure effect, whereby some of the personal characteristics that led people to specialize in philosophy also make them more likely to endorse the intersubjective validity of aesthetic judgment - in other words, it may be that the kind of people who are attracted to the field of philosophy (e.g., as a potential career path) were already more likely to endorse the intersubjective validity of aesthetic judgment, even before they began coursework in philosophy. Either, or both, of these forms of exposure could potentially explain why philosophers would be more likelyto perceive the intersubjective validity of aesthetic judgment. Respondents' "exposure" to philosophy was probed using the following question:

How much philosophy have you done during your education?

1. I have never taken any philosophy course

2. I have taken 1 or 2 philosophy courses

3. I have taken more than 2 philosophy courses, but philosophy is (or was) not the discipline I was (am) trained in

4. Philosophy is the discipline I am trained in, and I am getting an undergraduate degree in philosophy

5. Philosophy is the discipline I am trained in, and I have an undergraduate degree in philosophy

6. I am doing a graduate degree in philosophy

7. I have a $\mathrm{PhD}$ in philosophy 
TABLE 4 Distribution of answers as a function of exposure to philosophy

\begin{tabular}{|lllll|}
\hline Exposure & $\boldsymbol{N}$ & Answer 1 (\%) & Answer 2 (\%) & Answer 3 (\%) \\
\hline None & 1,127 & 7.0 & 41.3 & 51.6 \\
\hline 1 or 2 courses & 768 & 5.7 & 43.6 & 50.6 \\
\hline More than 2 courses & 321 & 5.3 & 31.5 & 63.2 \\
\hline Getting an undergraduate degree & 104 & 18.3 & 37.5 & 44.2 \\
\hline Got an undergraduate degree & 12 & 8.3 & 33.3 & 58.3 \\
\hline Doing a graduate degree & 20 & 15.0 & 45.0 & 40.0 \\
\hline PhD & 5 & 20.0 & 60.0 & 20.0 \\
\hline
\end{tabular}

Table 4 presents the distribution of respondents' responses as a function of their exposure to philosophy, and suggests that respondents who are more exposed to philosophy were more likely to select Answer 1. To more rigorously examine the relationship between exposure to philosophy and the likelihood of selecting Answer 1, we regressed the latter on the former, while simultaneously controlling for a host of other factors (as explained above). Furthermore, to tease apart the potential contributions of the two forms of exposure (exogenously- and endogenously-driven), we simultaneously entered two "exposure" predictors into the regression: The predictor of exogenous exposure to philosophy was our exposure measure coded as a continuous variable (i.e., a 1-7 scale, corresponding to the seven response categories); for our predictor of endogenous exposure to philosophy (i.e., self-selection), we used a binary coding of our exposure measure: responses 1-3 were coded as not having selected into philosophy, while responses 4-7 were coded as having selected into philosophy. Results revealed that exogenous exposure to philosophy (i.e., the amount of philosophy coursework) did not predict the likelihood of selecting Answer $1(-15.1 \%, \mathrm{p}=.24)$. However, endogenous exposure to (i.e., selection into) philosophy did positively predict respondents' likelihood of selecting Answer $1(+204.7 \%, \mathrm{p}<.05)$.

Thus, though experience with philosophy does not, in itself, increase the likelihood of perceiving aesthetic judgments as having intersubjective validity, it seems that the kinds of people who choose to specialize in philosophy (rather than other fields of study) were already more likely to endorse such claims. This might explain part of Bourget and Chalmers's (2014) results, as well as the apparent consensus regarding the perceived intersubjective validity of aesthetic judgment. Critically, however, Answer 1 is rarely chosen even by those who have a Master's or PhD degree in philosophy (see Table 4). Thus, even if selecting into philosophy does predict an increase in the likelihood of accepting the intersubjective validity of aesthetic judgment, our results nonetheless show that most people who specialize in philosophy do not actually endorse this claim (e.g., only $17 \%$ of respondents who selected into philosophy did so). So how can these results be reconciled with those of Bourget and Chalmers?

In fact, a closer look at Bourget and Chalmers's (2014) results show that, when one separates the answers of specialists in the area of aesthetics from those of non-specialists, only specialists in aesthetics turn out to be more likely to choose the "objective" answer, while non-specialists are in fact more likely to endorse the "subjective" answer than specialists in aesthetics. For example, only $26.12 \%$ of specialists chose the "subjective" answer, while $46.36 \%$ of non-specialists did.

Thus, while selecting into philosophy in general might somewhat increase the probability of endorsing the intersubjective validity of aesthetic judgment, high rates of endorsement seem better predicted by selecting into aesthetics specifically. This could be interpreted either to mean that the kinds of individuals who select into aesthetics as a field of study were already more likely to endorse the intersubjective validity of aesthetic judgment, or to mean that expertise in aesthetics leads philosophers to reach a better grasp of certain truths (e.g., that aesthetic judgments indeed have intersubjective validity), or as evidence of conformity among aestheticians. Regardless, these results are at odds with the claim that aesthetic judgments naturally appear to have intersubjective validity and that this is part of common sense and folk aesthetics. Rather, they suggest that, when specialists in aesthetics claim that aesthetic judgments naturally appear to have intersubjective validity, they might merely be projecting their own attitudes onto those of the general population, and thus mistaking their idiosyncratic beliefs for common sense.

\section{3 | METHODOLOGICAL CRITICISMS}


Overall, our results indicate that, across a wide range of countries and geographic areas, the vast majority of people do not attribute intersubjective validity to aesthetic judgment; rather, they tend to dismiss the idea that, if two people formulate opposite aesthetic judgments, one of them must be right, and the other wrong. These results are in line with previous research (Cova, in press; Cova \& Pain, 2012), and, this time, cannot be dismissed on the basis of our sample being small, not representative, or composed of superficially relativist Western students (Pouivet, 2006).

However, this does not mean that our results cannot be contested on other methodological grounds. For example, one might argue that participants' answers to our questions do not necessarily reflect their rejecting the intersubjective validity of aesthetic judgments, but can be explained in other, simpler ways. A first way is to claim that participants read our questions as bearing on their aesthetic judgments' justification, rather than on their truth. Note that, in our study, we asked participants whether it was true that one of the two interlocutors was "correct" while the other was not, and not about the truth-value of these interlocutors' claims. However, participants might think that being "correct" is not only about saying something true, but also about being justified in making this claim. Thus, supposing that neither interlocutor is perceived as being justified in his/her opinion, participants might end up answering that neither is correct, even if they think that one says something true while the other says something false (see Zangwill, in press, and Cova, in press, for a rejoinder).

A second way to explain away our results is to stress the fact that the interlocutors' claims in our vignette are not directly about whether the target object is beautiful, but about whether they find the target object beautiful. Therefore, one might argue, it is not surprising that most participants did not end up concluding that 'one is correct while the other is not': in fact, both are correct, simply because each one is making a claim about his or her own aesthetic assessment, and that there is no contradiction between two such claims. Indeed, it is perfectly consistent to say both that "A finds $\mathrm{x}$ beautiful" and "B does not find $\mathrm{x}$ beautiful."

Thus, according to both of these criticisms, our experimental design prevents us from drawing any substantial conclusions about people's endorsement of the intersubjective validity of aesthetic judgments. But are these criticisms warranted? If they are, then we should expect to obtain similar results for judgments to which it is clear that most people attribute intersubjective validity (e.g., descriptive, factual judgments). We thus decided to put this prediction to the test.

To this end, 214 participants were recruited through Amazon Mechanical Turk (118 men, 95 women, 1 other; $\mathrm{M}_{\mathrm{age}}=37.2, \mathrm{SD}_{\mathrm{age}}=12.9$; all U.S. residents) and randomly assigned to either the Descriptive disagreement or the Aesthetic disagreement condition. Participants in the Descriptive disagreement condition received the following vignette:

Imagine that you are walking through the countryside with some friends and enjoying the view, when suddenly you stop. You see a tower a few miles from here, but you are not sure whether it is a round or square tower. While trying to find out by looking at the tower, you say out loud:

"I think that this tower is round."

Now, imagine that someone near you hears what you just said and tells you that he does not think the tower to be round at all.

While participants in the Aesthetic disagreement condition received the following vignette:

Imagine that you are walking in a museum, visiting an art exhibition, when suddenly you stop by a painting. You find the painting to be incredibly beautiful, a real mastery work. While admiring the painting, you say out loud:

"I find this painting very beautiful."

Now, imagine that someone near you hears what you just said and tells you that he does not find this painting beautiful at all.

Then, participants in both conditions received the four following questions (Questions 1 and 2 were presented on one page, and Questions 3 and 4 on a separate page):

Question 1. In your personal opinion, which of the following best describes this situation:

1. One of you is correct while the other is not.

2. Both of you are correct.

3. Neither is correct. It makes no sense to talk about correctness in this situation. 
Question 2. How certain are you of your response to Question 1 on a (0-100)\% scale, with low numbers indicating that you are not sure and high numbers indicating that you are sure? I am $\%$ certain of my response.

Question 3. In your personal opinion, which of the following best describes this situation:

1. One of you says something true while the other says something false (even if we cannot necessarily know which one is which).

2. Both of you say something true.

3. Both of you say something false.

4. Neither say something true. It makes no sense to talk about truth in this situation.

Question 4. How certain are you of your response to Question 3 on a (0-100)\% scale, with low numbers indicating that you are not sure and high numbers indicating that you are sure?

I am $\%$ certain of my response.

Results for Questions 1 and 3 are presented in Figure 3. As can be seen, the results for the Aesthetic disagreement condition parallel those of our main study: for Question 1, only 13\% of participants chose to answer that "one is correct while the other is not"; for Question 3, only $12 \%$ chose to answer that "one says something true while the other says something false." This stands in sharp contrast with participants' answers in the Descriptive disagreement condition: for Question 1, 70.2\% chose to answer that "one is correct while the other is not"; for Question 3,64.9\% chose to answer that "one says something true while the other says something false." Moreover, participants' answers to Aesthetic and Descriptive disagreements differ significantly (Question 1: $\chi^{2}(1, \mathrm{~N}=214)=68.56, \mathrm{p}<.001$; Question 3: $\chi 2(1, \mathrm{~N}=214)=59.87, \mathrm{p}<.001$ ), which shows that participants did not treat aesthetic judgments the way they treat paradigmatic descriptive judgments. Moreover, the fact that "one is correct while the other is not" was the modal answer in the Descriptive disagreement condition implies that the two alternative accounts we described earlier are not enough to explain the results we observed in our main study (see Cova, in press, for further discussion).
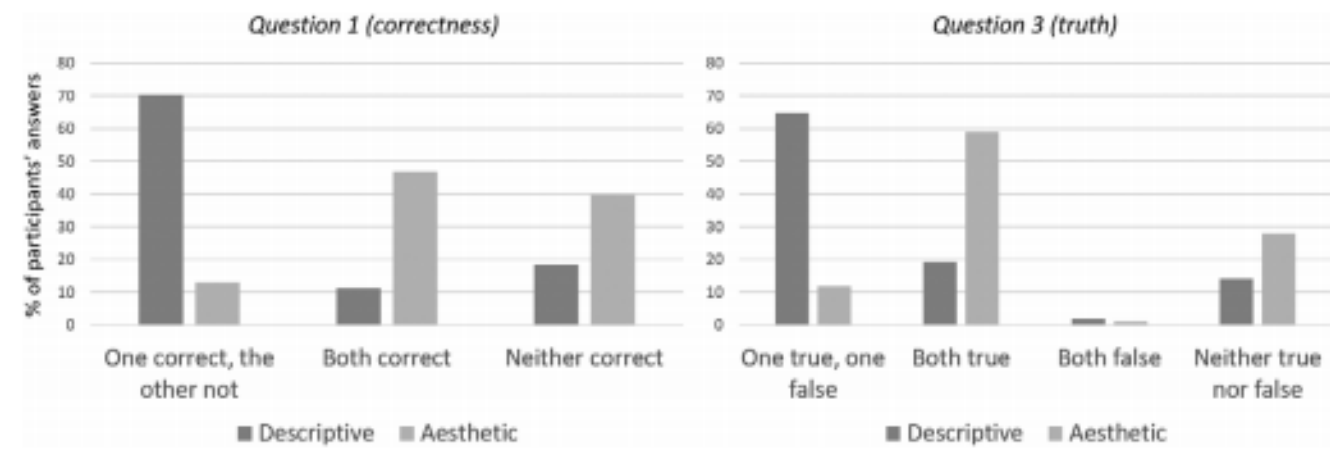

FIGURE 3 Percentage of answers to Questions 1 and 3 for each condition (Descriptive disagreement vs. Aesthetic disagreement) in the first follow-up study

Sure, the fact that only two thirds of participants chose this answer where we should have expected nearly all of them to select it might indicate that our experimental method was not optimal and this could have led us to somewhat overestimate the number of people who reject the intersubjective validity of aesthetic judgment. Future research might be better off using direct statements about objects ("this painting is beautiful" rather than "I find this painting beautiful") and asking about truth) values rather than correctness. ${ }^{2}$ Still, in spite of such considerations, the results of our main study indicate that most people

\footnotetext{
${ }^{2}$ To assess how much our design might have led us to overestimate the number of people who reject the intersubjective validity of aesthetic judgments, we ran another follow-up study, using only the Aesthetic disagreement vignette, with the following change in the wording at the end:
}

[...] you say out loud:

"This painting is beautiful."

Now, imagine that someone near you hears what you just said and tells you: "No, this painting it not beautiful at all." 
reject the intersubjective validity of aesthetic judgments. If this was not the case, we should have obtained results similar to the one we obtained for descriptive disagreements, with the majority of participants choosing the "one is correct while the other is not" answer.

\section{4 | GENERAL DISCUSSION}

\subsection{The role of common sense in theorizing about aesthetic judgment}

Despite some methodological worries, addressed above, it seems that we can take our results as showing that most people, in most countries, actually reject the intersubjective validity of aesthetic judgments. But what lessons should be drawn from our results? There are at least two. The first, and probably most obvious one, is that philosophical accounts such as aesthetic realism that relied on their alleged agreement with common sense can no longer do so. This is not to say that we have proven these theories to be false-we did not. However, one could argue that we undermined the plausibility of such theories by showing that one of their key justifications (that they agree with common sense) does not hold.

For example, as mentioned earlier, one widespread argument for aesthetic realism is the following (Caroll, 1999; Réhault, 2013; Zangwill, 2001): aesthetic realism (i.e., the existence of mind-independent aesthetic properties) is true because it provides the best explanation for the fact that people attribute intersubjective normativity to aesthetic judgments. This is obviously an inference to the best explanation. However, because our results suggest that what aesthetic realism purports to explain is not the case, so that there is nothing to explain, this argument can no longer provide evidence in favour of aesthetic realism. Thus, by drastically revising our beliefs about the content of common sense, our results undercut some powerful arguments for aesthetic realism. They also change the dialectical equilibrium: It is not true that those who reject aesthetic realism bear the burden of proof because they have to provide a compelling error theory explaining why common sense is committed to aesthetic realism (see Zangwill, 2005).

But do our results allow aesthetic anti-realists to claim that common sense is in their favour? Not necessarily. Indeed, as we saw, there are two main brands of aesthetic anti-realism: relativism and nihilism. While our results suggest that each of these positions is far more likely to be embraced by people than aesthetic realism, they also show that the likelihood of respondents favouring relativism over nihilism depends on their cultural background. Thus, none of these theories find definitive support on the basis of their alleged alignment with common sense, as there seems to be no such common sense. Doing so would thus require favouring the beliefs of some cultures over those of others - a choice that would inevitably be arbitrary (Machery, 2017).

The overall lesson is thus that philosophical accounts of aesthetic judgments should not take agreement with an alleged universal common sense as an argument in their favour, unless they are willing to embrace philosophical relativism and claim that the truth of philosophical accounts of aesthetic judgments is itself culture-dependent.

\subsection{The future of philosophical inquiry about aesthetic judgment}

The second and more important lesson that can be drawn from our results is that certain questions in philosophical aesthetics have been made intractable by the very way they have been framed. Determining the nature of aesthetic judgments is clearly an important goal of philosophical aesthetics. However, the philosophical debate has so far been framed in such a way that the question "what is aesthetic judgment?" has been interpreted to be "how can we reconcile the apparent intersubjective validity of aesthetic judgment with its apparent subjectivity?" Consequently, it has been widely assumed that answering the former question first requires obtaining an answer to the latter. However, our results suggest that the second question cannot be properly answered: there is no good explanation to be found for common sense's endorsement of the intersubjective validity of aesthetic judgments, because there is no such endorsementpeople do not perceive aesthetic judgments as having intersubjective validity.

We recruited 103 participants through Amazon Mechanical Turk (67 men, 36 women; $\left.\mathrm{M}_{\mathrm{age}}=35.0, \mathrm{SD}_{\mathrm{age}}=10.5\right)$. For Question 1, 23.3\% responded that 'one is correct while the other is not'; for Question 3, 24\% responded that 'one says something true, the other says something false. As a comparison, in our first follow-up study, these proportions were $13 \%$ and $12 \%$, respectively. Thus, to the extent that our original methods overestimated the proportion of people rejecting intersubjective validity, this overestimation is only around $10 \%$. 
Thus, our results suggest that the traditional way of approaching the debate over the nature of aesthetic judgment is fundamentally misguided. However, this does not mean that this debate should be put aside; only that we should start afresh, and free ourselves from the idea that a proper account of aesthetic judgment must explain how it can appear both subjective and intersubjectively valid. Of course, doing so will not be easy: It requires escaping the combined grasps and influences of both Hume (1762) and Kant (1790/1928), who contributed to the debate being framed in this particular way. Nonetheless, starting afresh might ultimately help us to make significant progress in our understanding of aesthetic judgment.

One concern might be that rejecting the traditional way of framing this question could make it less worthy of pursuit: After all, what made philosophical inquiry into the nature of aesthetic judgment particularly interesting was precisely this paradoxical mixture of subjectivity and apparent intersubjective validity. If we reject the apparent intersubjective validity of aesthetic judgment, then there seems to be nothing noteworthy about aesthetic judgment: It is just a subjective judgment much like any other, at least at first sight.

To this concern, we can offer three responses. The first is that truth does not have to be interesting or fascinating: there are simple and dull truths, but they are truths nonetheless. A proper account of aesthetic judgment might well belong to this category of truths. At least, there is no a priori reason to reject this possibility.

The second is that "mere subjective judgments" have often been taken to be simpler than they really are. It is common practice, at least since Kant (1790/1928), to contrast the intriguing intersubjective validity of aesthetic judgment with the obvious and transparent pure subjectivity of judgments about what is agreeable (the paradigmatic examples of which are gastronomic judgments, such as Kant's famous canary-wine). However, it seems that, upon closer examination, gastronomic judgments also have puzzling properties: though we seem to agree that gastronomic judgments are purely subjective, we also accept the existence of expert gastronomic critics, and we distinguish "crude" and "refined" gastronomic tastes. Similarly, whether something can be categorized as disgusting would probably be considered a typically subjective matter by most philosophers. But studies show that people are ready to claim that judgments about what is disgusting can be true or false, and have intersubjective validity, when the objects of these judgments are highly disgusting (Cova \& Ravat, 2008; Nichols \& Folds-Bennett, 2003). Thus, claiming that aesthetic judgments are "mere" subjective judgments does not imply that they are unworthy topics of investigation. There is still, it seems, much that we do not understand about "mere" subjective judgments.

The third and final response we can offer is that there are still many interesting questions to explore regarding aesthetic judgments, even if we deny that they naturally appear to us as having intersubjective validity. Indeed, as we pointed out in the introduction, the idea that aesthetic judgment is purely subjective seems to be at odds with some of our practices: We debate aesthetic matters, distinguish between good and bad taste, and accept the existence of expert art critics. Explaining how such practices can be reconciled with the fact that most of us take aesthetic judgments to be expressions of subjective preferences is an interesting and worthy task in itself.

Of course, one simple explanation for all these phenomena is that, though most of us do not realize it at a conscious level, we tacitly take aesthetic judgments to have intersubjective validity, and thus to be either correct or incorrect. In this framework, aesthetic disputes can be explained as a dispute about the truth or falsity of certain statements, good taste as the disposition to form accurate aesthetic judgments, and expert art critics as individuals with particularly good taste. Thus, the traditional claim that we naturally take aesthetic judgments to have intersubjective validity could be salvaged by dissociating the tacit commitments that guide our practices from explicit folk theories of aesthetic judgment that are contaminated by certain philosophical prejudices (Pouivet, 2006; Réhault, 2009).

However, this explanation faces serious challenges. First, in light of our results, it carries the weight of developing a full-fledged error theory: It must explain why people do not explicitly view aesthetic judgments as having intersubjective validity in spite of the fact that they tacitly take them to have intersubjective validity. In the absence of such an error theory, this alternative account is far from being the best explanation for the way people think about aesthetic judgment. Second, it also has to compete with alternative explanations. For example, the fact that we debate aesthetic judgments does not necessarily imply genuine aesthetic disagreements. An emotivist account of aesthetic judgment, according to which aesthetic judgments are mere expressions of subjective preferences, could use the same strategies that emotivists have used to explain moral disputes and describe aesthetic disputes as attempts to change others' attitudes towards a given object. In fact, such an account would even be consistent with certain accounts of aesthetic reasons, according to which giving aesthetic reasons is merely giving "directions for perceiving" - that is, pointing at 
features of an object in the hope that your interlocutor ends up seeing it in the same way you do (Isenberg, 1949; Sibley, 1965).

Similarly, the fact that we distinguish between "good" and "bad" taste does not necessarily commit us to accepting the existence of aesthetic truths. In fact, it is not even clear that our notion of good taste is best understood as some ability to better perceive aesthetic truths and aesthetic properties. An alternative explanation could be that good taste consists of aesthetic preferences that reveal character traits or intellectual dispositions we admire, while bad taste consists of preferences that signal undesirable traits. For example, many people consider it bad taste to enjoy racist jokes not because they cannot be funny, but because enjoying them could indicate immoral dispositions. Conversely, many people consider it good taste to enjoy "classic" works of literature, as it might indicate high intellectual ability. Not only would such a theory fall directly in line with sociological accounts of aesthetic taste (e.g., Bourdieu, 1984), it would also be consistent with recent empirical results. For example, Goffin and Cova (2018) recently investigated "guilty pleasures" - occasions in which people feel bad about enjoying a given work of art. They observed that people's feelings of guilt (and, more generally, their negative feelings) were not predicted by whether they saw the work of art as aesthetically deficient, but rather by considerations about what their enjoyment revealed about them (on both a moral and intellectual level). Their results suggest that our classification of tastes has more to do with what aesthetic preferences reveal about people's moral and intellectual abilities than with any (hypothetical) ability to perceive aesthetic truths.

Thus, it could be that people might still endorse the intersubjective validity of aesthetic judgment at a tacit level. But this is just one of the many possible explanations for a certain range of phenomena (the reality and universality of which can also be discussed). In light of our results, there is no reason to award this explanation a privileged status and erect it as a default theoretical position. If some philosophers feel it is worth developing accounts around the assumption of a tacit belief in the intersubjective validity of aesthetic judgment, they are certainly free to do so. However, philosophical inquiries about the nature of aesthetic judgments should no longer take the (explicit) belief in intersubjective validity (and how to explain it) as a starting point. Rather, they should embrace the whole range of phenomena that need to be explained with a fresh look. Now is the time to try to develop novel accounts of aesthetic judgments. And this is a task for philosophical aesthetics.

\section{ACKNOWLEDGMENTS}

This publication was made possible through the support of a grant from the Fuller Theological Seminary/Thrive Center in concert with the John Templeton Foundation. The opinions expressed in this publication are those of the authors and do not necessarily reflect the views of the Fuller Thrive Center or the John Templeton Foundation. F.C.'s work on this publication was funded by the Cogito Foundation (Zurich) as part of project S-131/13 ("Towards an experimental philosophy of aesthetics").

\section{REFERENCES}

Bourdieu, P. (1984). Distinction. A social critique of the judgement of taste. London: Routledge \& Keegan Paul.

Bourget, D. \& Chalmers, D. J. (2014). What do philosophers believe? Philosophical Studies, 170(3), 465500.

Budd, M. (2007). The intersubjective validity of aesthetic judgements. British Journal of Aesthetics, 47(4), 333-371.

Caroll, N. (1999). Philosophy of art: A contemporary introduction. London: Routledge.

Cova, F. (in press). Beyond intersubjective validity: Recent empirical investigations into the nature of aesthetic judgment. In F. Cova \& S. Réhault (Eds.), Advances in experimental philosophy of aesthetics. London: Bloomsbury.

Cova, F., Garcia, A. \& Liao, S. Y. (2015). Experimental philosophy of aesthetics. Philosophy Compass, 
10(12), 927-939.

Cova, F. \& Pain, N. (2012). Can folk aesthetics ground aesthetic realism? The Monist, 95(2), 241-263.

Cova, F. \& Ravat, J. (2008). Sens commun et objectivisme moral: Objectivisme « global» ou objectivisme « local »? Une introduction par l'exemple à la philosophie expérimentale. Klesis, 9, 180-202.

Frederick, S. (2005). Cognitive reflection and decision making. Journal of Economic Perspectives, 19, 2542.

Genette, G. (1997). L'oeuvre de l'art, II: La relation esthétique. Paris: Seuil.

Goffin, K. \& Cova, F. (2018). An empirical investigation of guilty pleasures (Unpublished manuscript). University of Geneva.

Goldman, A. H. (1995). Aesthetic value. Boulder, CO: Westview Press.

Henrich, J., Heine, S. J. \& Norenzayan, A. (2010). The weirdest people in the world? Behavioral and Brain Sciences, 33(2-3), 61-83.

Hopkins, R. (2001). Kant, quasi-realism, and the autonomy of aesthetic judgement. European Journal of Philosophy, 9(2), 166-189.

Hume, D. (1762). Of the standard of taste. In Four dissertations (pp. 203-240). London: A. Millar.

Isenberg, A. (1949). Critical communication. The Philosophical Review, 58, 330-344.

Kant, I. (1790/1928). Critique of judgment. Oxford: Oxford University Press.

Kivy, P. (2015). De gustibus: Arguing about taste and why we do it. Oxford: Oxford University Press.

Livengood, J., Sytsma, J., Feltz, A., Scheines, R. \& Machery, E. (2010). Philosophical temperament. Philosophical Psychology, 23(3), 313-330.

Machery, E. (2017). Philosophy within its proper bounds. Oxford: Oxford University Press.

Mackie, J. (1990). Ethics: Inventing right and wrong. London: Penguin UK.

Nichols, S. \& Folds-Bennett, T. (2003). Are children moral objectivists? Children's judgments about moral and response-dependent properties. Cognition, 90(2), B23-B32.

Pouivet, R. (2006). Le réalisme esthétique. Paris: Presses Universitaires de France.

Réhault, S. (2009). Réalisme esthétique, éthique et environnement. Klesis, 13, 123-146.

Réhault, S. (2013). La beauté des choses. Rennes: Presses universitaires de Rennes.

Robson, J. (2012). Aesthetic testimony. Philosophy Compass, 7(1), 1-10.

Schellekens, E. (2009). Taste and objectivity: The emergence of the concept of the aesthetic. Philosophy Compass, 4(5), 734-743.

Sibley, F. (1965). Aesthetic and nonaesthetic. The Philosophical Review, 74(2), 135-159.

Todd, C. (2004). Quasi-realism, acquaintance, and the normative claims of aesthetic judgement. British Journal of Aesthetics, 44(3), 277-296.

Vandenabeele, B. (2008). The subjective universality of aesthetic judgements revisited. British Journal of Aesthetics, 48(4), 410-425.

Zangwill, N. (2001). The metaphysics of beauty. New York, NY: Cornell University Press.

Zangwill, N. (2005). Aesthetic realism. In J. Levinson (Ed.), The Oxford handbook of aesthetics (pp. 63-79). Oxford: Oxford University Press.

Zangwill, N. (2010). Aesthetic judgment. In E. N. Zalta (Ed.), Stanford Encyclopedia of Philosophy. Retrieved from http://plato.stanford.edu/entries/aesthetic-judgment/

Zangwill, N. (in press). Beauty and the agreeable: A critique of experimental aesthetics. In F. Cova \& S. Rehault (Eds.), Advances in experimental philosophy of aesthetics. London: Bloomsbury. 